\title{
Economical and Ecological Electric Heaters for Room Heating
}

\author{
A.I. Aliferov \\ Novosibirsk State Technical University \\ Novosibirsk, Russia \\ aliferov@corp.nstu.ru \\ V.A. Vdovin \\ Novosibirsk State Technical University \\ Novosibirsk, Russia \\ aliferov@corp.nstu.ru
}

\author{
D.S. Vlasov \\ Novosibirsk State Technical University \\ Novosibirsk, Russia \\ aliferov@corp.nstu.ru
}

\author{
A.S. Anshakov \\ Kutateladze Institute of Thermophysics SB RAS \\ Novosibirsk, Russia \\ anshakov@itp.nsc.ru
}

\author{
A.E. Urbah \\ Kutateladze Institute of Thermophysics SB RAS \\ Novosibirsk, Russia \\ anshakov@itp.nsc.ru
}

\begin{abstract}
Comparative analysis of various electric heating elements used for room heating is presented. Advantages of flat plasma-sprayed electrical heaters in terms of energetic and thermal parameters are shown. Dependencies of specific surface power and temperature distribution through heater substrate width upon thermal conductivity and geometrical parameters of the substrate are pictured. Experimentally measured dependency of specific resistivity of the sprayed ohmic chrome-nickel layer is given. Thermal and electrical experimental characteristics of the flat two-lane plasma-sprayed heater are also presented.
\end{abstract}

Keywords-human thermal comfort; electric heating equipment; plasma-sprayed flat electric heaters; specific surface power; heater temperature distribution; heater volt-ampere characteristic

\section{INTRODUCTION}

Thermal comfort implies such physiological state, in which human central nervous system gets the least possible number of external irritants. The most substantial irritants that could be weakened or eliminated are: higher or lower average room temperature, unevenness of volumetric temperature field and dust suspension in the room atmosphere. Hygienic guidelines for comfort thermal state of rooms and premises in case of convective-radiative winter heating define optimal temperature in the range of $16 \ldots 26^{\circ} \mathrm{C}$, depending on the purpose of premises and people's activity form there.

It is noticed that an offensive odor emerges in the room, after switching on some heating devices. The reason is sublimation and burning of dust suspension adhered to the heater element surface. It causes oxygen percentage decrease and harmful oxides $\left(\mathrm{CO}_{2}\right.$ and others) content increase in the air of the heated room. Hygienic guidelines [1] inform that gases generated in dust sublimation irritate respiratory tracts mucous coat, causing throat dryness and headaches. Dust burning will not occur if the heating device surface temperature does not exceed $70 \ldots 85^{\circ} \mathrm{C}$.

\section{ECOLOGICAL Electric HEATERS}

Analysis of thermal and aerodynamic working states of electrical heating devices uncovers that most ecological heaters do not create forced air circulation in the heated room and temperature of their air-contacting surfaces is less than $85^{\circ} \mathrm{C}$. These include oil electric radiators, plastic on-wall heating panels, flat heaters, convectors and others. Such heating devices do not create intensive circulating air-dust flows, unlike fan heaters, do not burn-out oxygen and do not sublimate dust down to harmful fractions, unlike radiative heating devices (fireplaces and reflective heaters) or convection heating devices, which are equipped with fans and have air-contacting heating elements with surfaces temperature of $300-500{ }^{\circ} \mathrm{C}$.

Oil-filled electric radiators are the most ecological heating devices. Heating a room by natural convection and radiation, they have outer surface temperature less than $85^{\circ} \mathrm{C}$. But electric radiators have a big disadvantage - complex design.

Plastic wall panel heating electric devices develop maximal working temperature of their outer surface less than $85^{\circ} \mathrm{C}$. Being ecological both in design and work mode, such devices show poor energetic efficiency. Low values of specific surface power of the panel heaters are defined by uneven temperature distribution on heat-releasing surface and weak thermal endurance. Improvement of thermal field evenness of such heaters is coupled with complication of their design.

One of alternative variants of heaters, which provide both high ecological and enhanced energetic parameters, are plasma-sprayed flat heating elements, developed at the 
Institute of Thermophysics SB RAS in cooperation with Department of Automated Electrotechnological Installations of Novosibirsk State Technical University [2]-[6].

\section{DESIGN OF THE Flat PlaSMA-SPRAYED HEATERS}

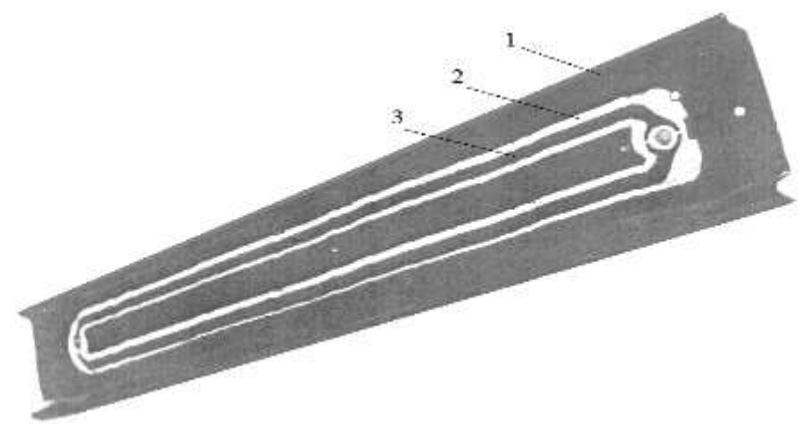

Fig. 1. Flat plasma-sprayed heater: 1 - steel substrate; 2 - sprayed electroisolative layer; 3 - ohmic layer; outer electro-isolative layer is not shown.

The plasma-sprayed flat heater (Fig. 1) is a steel plate, called substrate, one face of which is coated consequently by three layers: electrical isolation, ohmic material and electrical isolation. The steel plate is made of structural steel St.3, and has dimensions $150 \times 900 \times 2 \mathrm{~mm}$. Electrical isolation layers are formed by $\mathrm{Al}_{2} \mathrm{O}_{3}$ powder and have thickness $150 \ldots 200 \mathrm{mcm}$. The ohmic layer, having thickness of $100 \mathrm{mcm}$, is formed from powder with $80 \%$ of nickel and $20 \%$ of chrome.

In production of the presented sample heater, the substrate, steel plate, firstly has been annealed, next, bead-blasted with electrocorundum granules of $1 \ldots 2 \mathrm{~mm}$ size at 6 atmospheres of air pressure.

After that, a layer of nickel-aluminum powder PN85U15, $40-70 \mathrm{mcm}$ particles, has been sprayed. The width of the layer has been made about $22 \mathrm{~mm}$, thickness $-50 \ldots 100 \mathrm{mcm}$. The layer of $\mathrm{NiAl}$ is needed for reliable adhesion of the isolative $\mathrm{Al}_{2} \mathrm{O}_{3}$ layer to the steel substrate. During the plasma-spraying, nitrogen was used as working gas, and argon - as shielding and carrier gas. Arc discharge current was set to $I=140 \ldots 150$ A, arc voltage $-160 \mathrm{~V}$.

The isolative layer is formed with the $\mathrm{Al}_{2} \mathrm{O}_{3}$ powder, which particle size was in range $30 . .50 \mathrm{mcm}$. Thickness of the isolative layer was $200 \mathrm{mcm}$; width was about $20 \mathrm{~mm}$. Electrical mode of plasmatron is: arc discharge current - about $250 \mathrm{~A}$, arc voltage $-160 \mathrm{~V}$.

The current carrying resistive lane has been sprayed on top of the isolative $\mathrm{Al}_{2} \mathrm{O}_{3}$ layer. Powder composition was $80 \%$ of nickel and $20 \%$ of chrome; particles' size ranged between $30 \ldots .50 \mathrm{mcm}$. The thickness of the resistive layer was $150 \mathrm{mcm}$; the width of each lane was $10 \mathrm{~mm}$, and the length $750 \mathrm{~mm}$. The resistive layer was almost 1.5 times thicker near an electrical feed. Arc discharge current was set to $\mathrm{I}=130 \mathrm{~A}$, arc voltage $-160 \mathrm{~V}$.

After the ohmic layer is sprayed, stencil masks are changed, and the resistive lanes are covered by the layer of aluminum oxide to reduce the access of oxygen to the lanes. This measure greatly increases the service life of the heating element.

\section{PARAMETERS OF THE FlAT PLASMA-SPRAYED ElECTRIC} HEATER

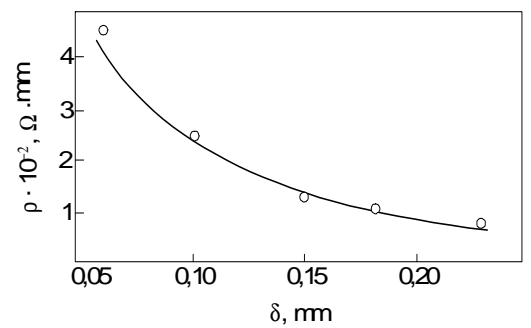

Fig. 2. Empirical dependency of specific electrical resistivity of sprayed chrome-nickel layer on its thickness.

Experimental investigation results of the heater parameters, presented in [5] and [6], have uncovered significant dependency of specific electrical resistivity of the sprayed chrome-nickel layer on its thickness, as shown in Fig. 2. Obviously, the thicker the layer, the smaller the resistivity. In the range of the layer thickness variation of $50 \ldots 150 \mathrm{mcm}$, the value of specific resistivity changes 4.5 times. After $150 \mathrm{mcm}$ thickness, the specific resistivity decreases slowly, so this thickness value has been chosen to build the sample heater.

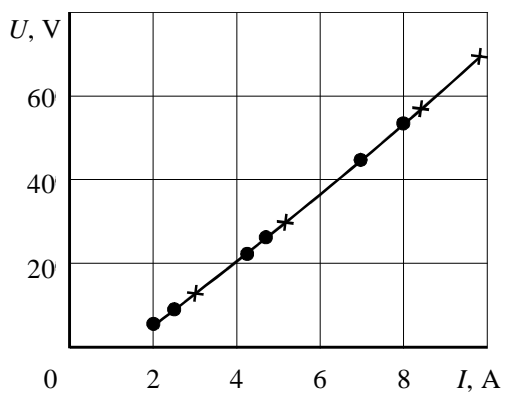

Fig. 3. Volt-ampere characteristic of the sample flat plasma-sprayed heater for alternating $(\mathrm{x})$ and direct $(\bullet)$ current.

Fig. 3 shows a volt-ampere characteristic flat plasmasprayed heater with dimensions $150 \times 900 \mathrm{~mm}$, with 2 parallel ohmic lanes of $10 \mathrm{~mm}$ width and $750 \mathrm{~mm}$ length each. The graph illustrates that points for feeding with direct and alternating current on mains frequency are in good agreement. It means that one and the same heater is equally effective both for direct and alternating current execution. The volt-ampere characteristic of the heater is slightly nonlinear, as expected for ohmic resistance, growing with temperature.

Fig. 4 shows measured dependency of heater surface temperature of the resistive layer axis upon flowing current at ambient temperature of $18{ }^{\circ} \mathrm{C}$.

Temperature measurements along the width of the lane have been also made. There could be significant overheating of the internal area of the curved part of the heating element due to uneven distribution of heating sources through width in the curved part, that depends on the curve radius and the lane width. While thermal expansion coefficients of layers are different, the isolative layer can be torn off the substrate, thus causing cracking and complete failure of the heater, if the 
device local temperature reaches a certain critical value. Expert judgement on the critical temperature for the used materials is near $350{ }^{\circ} \mathrm{C}$. So, it is necessary to ensure that this failure is unlikely to happen for given lanes' geometry.

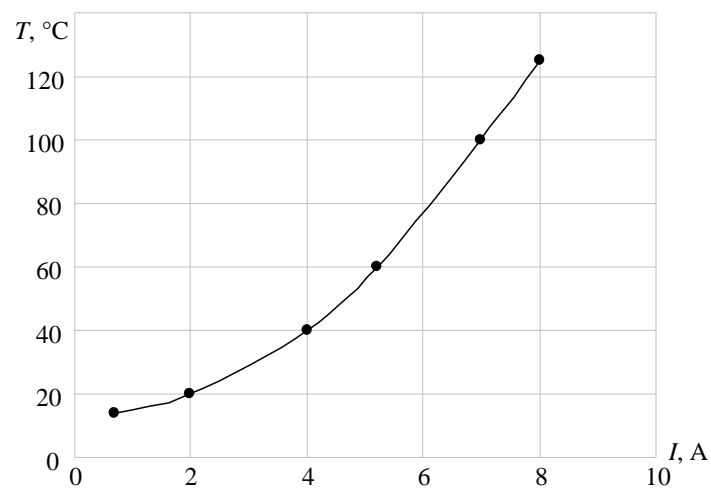

Fig. 4. Empirical dependency of heater surface temperature of resistive layer axis upon flowing current.

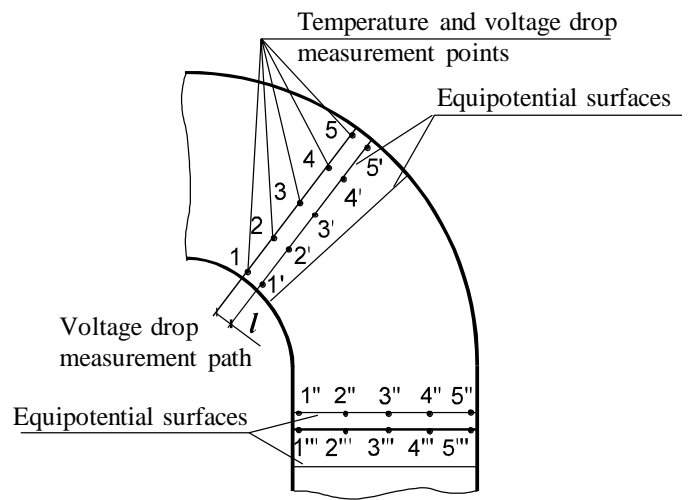

Fig. 5. Curved fragment of resistive lane.

Fig. 5 depicts a part of the heater lane, where the lane is curved towards electrical feed; the outer radius of the bend is $20 \mathrm{~mm}$. Locations of measurements points for temperature and current field in the lane and found equipotential surfaces are also shown there. Equipotential surfaces have been estimated with the help of a micro-ammeter and two $50 \mathrm{mcm}$ probes. According to experiments, the equipotential surfaces are drawn as straight lines, which are parallel to each other where the lane is straight and diverged in the bend area.

Fig. 6 presents temperature distribution over the width of the resistive lane in the curved region. Fig. 7 shows the experimental dependency of normalized electric field strength and current density on the radial coordinate of the curved part. These graphs indicate that heat release on the curved part of the lane is inhomogeneous - it is higher on the internal part of the bend than on the outer one; meanwhile heat release on the straight part of the lane is homogeneous. For the examined construction of the heater, in declared working temperature, observed temperature unevenness through ohmic lane width does not affect the heater operability. But in case of higher working temperatures, the overheat can be significant and sufficient to destroy the resistive layer as was described previously.
Fig. 8 presents dependency of average specific surface power of flat plasma-sprayed (1) and wall panel (2) heaters on their maximal surface temperature.

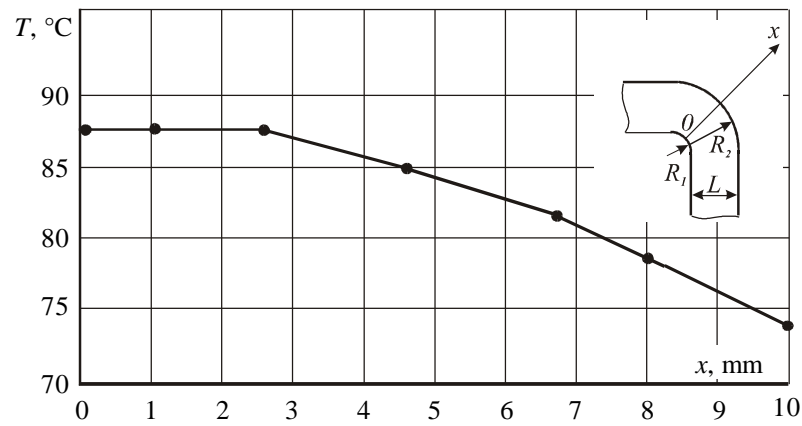

Fig. 6. Distribution of temperature over resistive lane width in curved area.

Comparison of these operating characteristics shows that for the range of the maximal allowed heater temperature of $50 \ldots 85^{\circ} \mathrm{C}$, specific surface power of flat plasma-sprayed heater exceeds that power of the plastic panel heater 1.8...2.1 times.

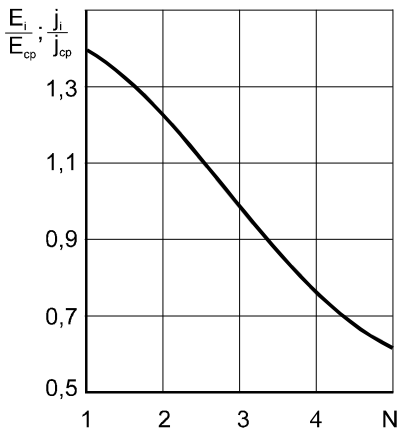

Fig. 7. Distribution of electric field strength and current density over width of resistive lane in bend zone: $\mathrm{N}$ - number of measurement point.

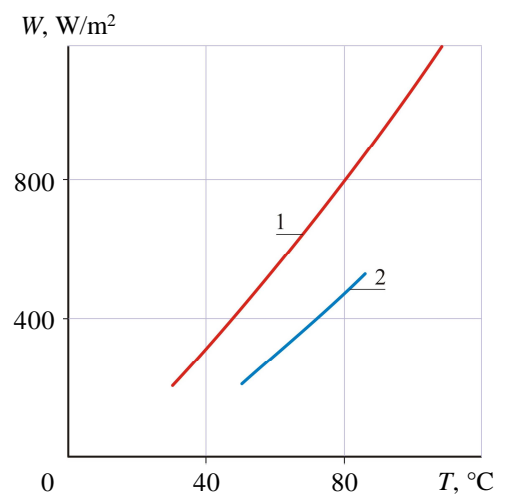

Fig. 8. Dependence of specific surface power on surface temperature for flat plasma-sprayed (1) and plastic on-wall panel (2) heaters.

Fig. 9 shows dependencies of specific surface power of the flat heater on substrate thickness and thermal conductivity. Examined heaters had substrate with the width of $150 \mathrm{~mm}$ with a sprayed single resistive lane $10 \mathrm{~mm}$ wide, or few parallel resistive lanes of the same width. Quantity $a / b$ for Fig. 9 is the ratio of the distance between resistive lanes of the multi-lane heater to the one lane width. 
Presented characteristics have been calculated from the mathematical model that provides thermal fields distribution over the cross-section of the heater, considering properties and geometry of its four layers. The model is based on a finitedifference solution of the differential equations system of heat conduction, which describes heat transfer in all layers of the heater. The third kind of the boundary condition is applied to all outer surfaces, releasing heat by convection and radiation, and the coupling boundary condition - to layers' interfaces. The model presents the dependence of the heat-transfer coefficient upon temperature of the steel plate substrate surface. Since heat transfer from the heater to the ambient air occurs by means of radiation and convection, an effective heat-transfer coefficient has been used to describe both types of heat transfer at once:

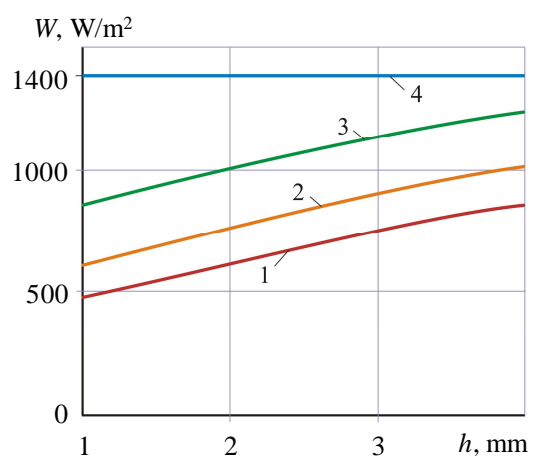

a)

$$
\begin{gathered}
\alpha_{\text {eff }}=\alpha_{\text {rad }}+\alpha_{\text {con }}= \\
=\frac{5,67 \cdot \varepsilon\left[\left(\frac{T_{h}}{100}\right)^{4}-\left(\frac{T_{a}}{100}\right)^{4}\right]}{t_{h}-t_{a}}+0,54(G r \cdot P r)_{a v}^{0,25}
\end{gathered}
$$

where $\alpha_{\text {rad }}$ - radiation heat-transfer coefficient, $\alpha_{c o n}-$ convection heat-transfer coefficient [7], $\varepsilon-$ heater emissivity, $T_{h}, T_{a}, t_{h}, t_{a}$ - heater and ambient temperature in Kelvins and Celsius degrees, correspondingly, $\mathrm{Gr}$ and $\mathrm{Pr}-$ Grasgof and Prandtl numbers; lower index $a v$ indicates that air physical properties for average temperature of the boundary layer have been used. The effective heat-transfer coefficient has been found to be independent of heater orientation - horizontal or vertical - due to its small size.

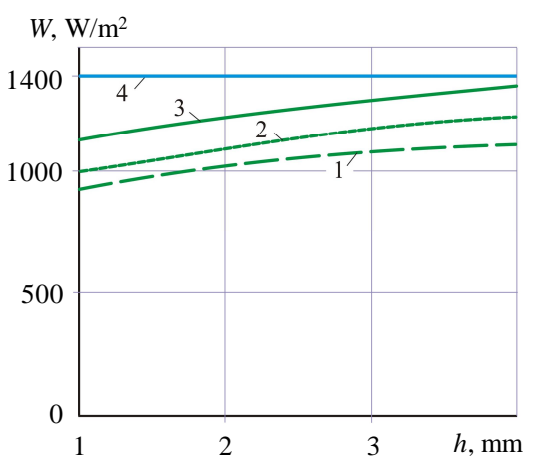

b)

Fig. 9. Dependency of specific surface power of flat plasma-sprayed heater upon metallic substrate thickness $h$ : a) one lane, maximal substrate temperature $T_{\max }=85^{\circ} \mathrm{C}$, various substrate thermal conductivities: $1-\lambda=30 \mathrm{~W} / \mathrm{m} / \mathrm{K} ; 2-\lambda=60 \mathrm{~W} / \mathrm{m} / \mathrm{K} ; 3-\lambda=120 \mathrm{~W} / \mathrm{m} / \mathrm{K} ; 4-\lambda=\infty-$ corresponds to "ideal" flat heater; b) multi-lane, various ratio of distance between lanes to lane width: $\lambda=30 \mathrm{~W} / \mathrm{m} / \mathrm{K}: 1-a / b=3,2-a / b=2,3-a / b=1 ; \lambda=\infty: 4-$ any $a / b$ value.

Fig. 10 presents dependencies of temperature distribution through the substrate width for a single-lane and multi-lane flat plasma-sprayed heater on thickness and thermal conductivity of the substrate material. In addition, even temperature field is observed for bigger thickness and bigger thermal conductivity. Presence of several lanes also decreases temperature differentials over the substrate width.

Presented graphs are plotted for a set of different substrate thermal conductivities, corresponding to a set of possible materials of the substrate: stainless steel $-\lambda=30 \mathrm{~W} / \mathrm{m} / \mathrm{K}$, quality steel $-\lambda=60 \mathrm{~W} / \mathrm{m} / \mathrm{K}$ and aluminum $-\lambda=120 \mathrm{~W} / \mathrm{m} / \mathrm{K}$. Graphs show that specific surface power of the heater grows with substrate thermal conductivity and thickness.
Calculations, which results are presented in Fig. 9 and Fig. 10 , reveal that specific surface power, released by the flat plasma-sprayed heater, rises with substrate temperature field evenness. Obviously, maximal specific surface power for the given maximal heater surface temperature will be reached due to perfectly even temperature distribution over its surface, like in an "ideal heater". Graphs in Fig. 10 show that the plasmasprayed flat heater is ideal enough for the substrate thickness range of $2 \ldots 4 \mathrm{~mm}$.

Dependency of the ratio of maximal temperature differential $\Delta T$ to maximal temperature for multi-lane heater $T_{\max }$ on $a / b$-ratio for various substrate thickness $h$, maximal temperature $T_{\max }=85^{\circ} \mathrm{C}$, and thermal conductivity $\lambda=30$ $\mathrm{W} / \mathrm{m} / \mathrm{K}$ is presented in Fig. 11. 


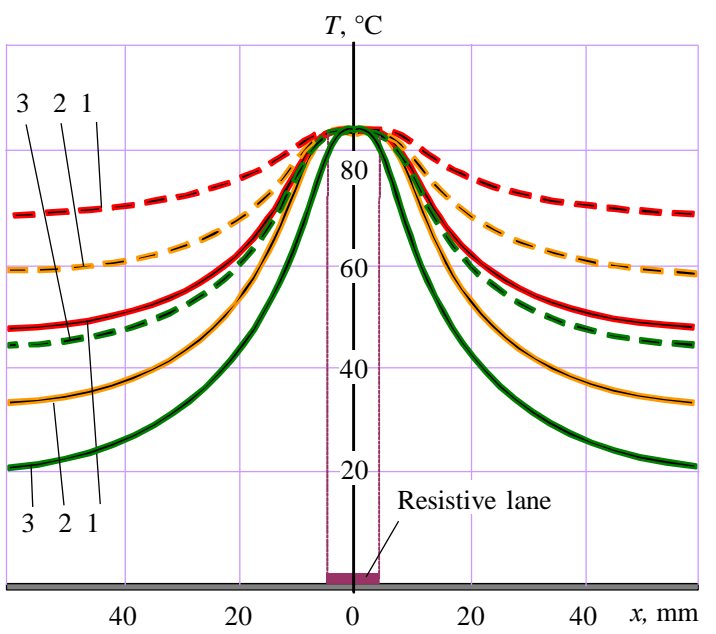

a)

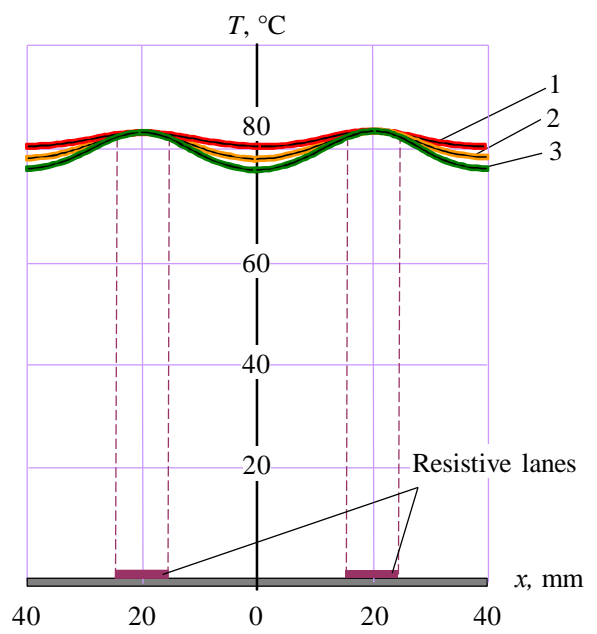

b)

Fig. 10. Distribution of temperature through width of substrate of flat plasma-sprayed heater for its temperature of $85{ }^{\circ} \mathrm{C}, x-\operatorname{coordinate}$ along width of the substrate: a) one lane of $10 \mathrm{~mm}$ width, various thermal conductivity and substrate thickness: $1-\lambda=120 \mathrm{~W} / \mathrm{m} / \mathrm{K} ; 2-\lambda=60 \mathrm{~W} / \mathrm{m} / \mathrm{K} ; 3-\lambda=30 \mathrm{~W} / \mathrm{m} / \mathrm{K}$; $(-)-h=1 \mathrm{~mm} ;(---)-h=4 \mathrm{~mm} ; x=0$ corresponds to longitudinal axis of lane; b) multiple lanes of 2 mm width, various thermal conductivity: $1-\lambda=120$ $\mathrm{W} / \mathrm{m} / \mathrm{K} ; 2-\lambda=60 \mathrm{~W} / \mathrm{m} / \mathrm{K} ; 3-\lambda=30 \mathrm{~W} / \mathrm{m} / \mathrm{K} ; x=0$ corresponds to position in the middle between two adjacent lanes.

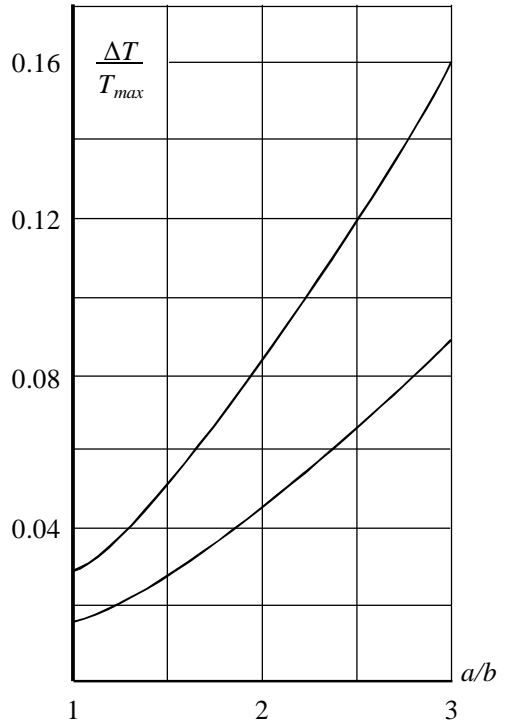

Fig. 11. Dependency of temperature filed evenness in substrate of multi-lane heater on $a / b$-ratio for $T_{\max }=85^{\circ} \mathrm{C}$ and $\lambda=30 \mathrm{~W} / \mathrm{m} / \mathrm{K}$.

\section{DESIGN PROCEDURE}

Both the results of presented calculations and experimental data ([5], [6]) show that it is quite easy to approach parameters of the "ideal heater" with a multi-lane design of the flat plasma-sprayed heater. So, this heater design variant should be chosen as a base for industrial heaters' development. The design procedure for such heater should look like the following example, which uses graphs in Fig. 9b and Fig. 11 for substrate thermal conductivity $\lambda=30 \mathrm{~W} / \mathrm{m} / \mathrm{K}$ :

1. For the needed value of total heater power $P$ and its surface area $F$, let us evaluate specific surface power $W=P / F$.
2. For the needed value of $\Delta T / T_{\max }$ (maximal temperature differential $\Delta T$ relatively maximal temperature for multi-lane heater $T_{\max }$ ) with the help of Fig. 11, let us evaluate values' ranges for $a / b$-ratio and substrate thickness $h$.

3. For known values $a / b$ and $W$, with the help of Fig. 9b, let us evaluate the ratio of substrate plate parameters $(\lambda$ and $h)$.

4. Let us valuate the ratio of the length to the width for the ohmic lane by formula $l / b=U^{2} \delta /(P \rho)$, where $U$ - voltage to be applied to the ohmic lane, $\delta$ - thickness of the ohmic lane, $\rho-$ specific electrical resistivity of the ohmic lane.

\section{CONCLUSIONS}

Experimental investigation of temperature modes and electrical characteristics of flat plasma-sprayed heating devices, subsequent experimental data processing and theoretical investigations provided possibility to perform comparative evaluation of their energetic characteristics with those for plastic on-wall panel heaters.

Having the same level of ecological compatibility (temperature and air-dust flows generation), congruous design complexity and materials consumption, the flat heater is more energetically effective. Its higher energetic efficiency arises from closeness of its operating characteristics (ratio of maximal surface temperature and average specific surface power) to these for an "ideal heater", which is a flat heater mainly characterized by even surface temperature field.

It is worth mentioning that plasma-sprayed heaters can have a substrate as volumetric surface, lanes can be organized in an any pattern, and surface working temperature can be in the range from $5{ }^{\circ} \mathrm{C}$ to $300{ }^{\circ} \mathrm{C}$. So, they could find an application not only in room heating, but also in technological heating installations, used, for example, in oil and gas industry. 


\section{References}

[1] Yu.P. Pivovarov, Hygiene and the basics of human ecology: a textbook for students of higher medical schools. Moscow: Academy, 2006.

[2] A.S. Anshakov, A.I. Aliferov, A.M. Kazanov, E.K. Urbakh, "Electricarc plasma generator for treating the powder materials", Thermophysics and Aeromechanics, vol. 2, pp. 215-222, 1998.

[3] V.S. Cherednichenko, A.S. Anshakov, A.I. Aliferov, "Resource-saving electrotechnics and equipment", Proc. of the 2nd Korea-Russia International Industry-University Cooperation Forum, pp. 67-74, 2005 $\left[2^{\text {nd }}\right.$ Korea-Russia International Industry-University Cooperation Forum, 2005]

[4] A.I. Aliferov, A.S. Anshakov, A.A. Danilenko, E.K. Urbakh, A.E Urbakh, "Arc plasma generator for deposition of powder coating", Proceedings of the Third International Forum on Strategic Technologies, pp. 378-382, June 23-29, 2008 [Third International Forum on Strategic Technologies - IFOST, 2008].
[5] A.I. Aliferov, E. Urbukh, "Energy saving electroheaters for household heating", Proceedings of The 4th Russian-Korean international symposium on Science and Technology, pp. 194-196, 2000 [4th Russian-Korean international symposium on Science and Technology KORUS-2000, 2000].

[6] A.S. Anshakov, A.I. Aliferov, V.A. Faleev, E.K. Urbakh, T.V. Khatsevskaya, "Electric heater development by means of plasma spraying", Proceedings of The 6th Russian-Korean international symposium on Science and Technology, pp. 214-218 [6th RussianKorean international symposium on Science and Technology, KORUS2002, 2002].

[7] S. Lupi, M. Forzan, A. Aliferov, Induction and direct resistance heating: theory and numerical modeling. Heidelberg: Springer, 2015. - ISBN 978-3-319-03478-2, eISBN 978-3-319-03479-9, DOI 10.1007/978-3319-03479-9. 